\title{
Rapid Publication
}

\section{Low Sodium Diet Corrects the Defect in Lymphocyte $\beta$-Adrenergic Responsiveness in Hypertensive Subjects}

Ross D. Feldman, William J. Lawton, and Wendy L. McArdle

Departments of Internal Medicine and Pharmacology, University of Iowa College of Medicine, Iowa City, Iowa 52242

\begin{abstract}
To determine the role of dietary sodium intake in the reduction in $\beta$-adrenergic sensitivity in hypertension, lymphocyte $\beta$-receptors from 8 borderline hypertensive and 16 normotensive subjects were studied after $5 \mathrm{~d}$ on a high sodium diet $(400 \mathrm{meq} / \mathrm{d})$ and also following a low sodium diet $(10 \mathrm{meq} / \mathrm{d})$. During the high sodium diet, lymphocyte $\beta$-receptor-stimulated adenylate cyclase activity, expressed as the relative increase over basal levels stimulated by the $\beta$-agonist isoproterenol, was significantly ( $P$ $<0.025)$ decreased in hypertensive $(24 \pm 5 \%$, mean \pm SE) compared with normotensive $(42 \pm 4 \%)$ subjects. Neither $\beta$-receptor density nor the proportion of nonsequestered $\beta$-receptors differed between groups. A low sodium diet significantly increased $\beta$ receptor-stimulated adenylate cyclase activity in hypertensives (low sodium, 51 $\pm 7 \%$; high sodium, $24 \pm 5 \%, P<0.025$ ) to a level not different than that of normotensives $(46 \pm 5 \%)$. Thus, reduced lymphocyte $\beta$-receptor responsiveness in hypertensive subjects is not due to $\beta$-receptor sequestration and is corrected on a low sodium diet. Dietary sodium may be an important factor in the $\beta$-receptor defect in early hypertension.
\end{abstract}

\section{Introduction}

Responsiveness to catecholamines is altered in hypertension and may be important in the pathogenesis and maintenance of the hypertensive state. In several animal models of hypertension, $\beta$-adrenergic receptor $(\beta A R)^{1}$ responsiveness is reduced (1-3). To explain this alteration, investigators have focused on the $\beta A R$-adenylate cyclase complex. Most have reported a reduction in $\beta A R$-mediated adenylate cyclase activity consistent with a reduction in $\beta A R$ responsiveness (4-8).

In humans, the lymphocyte $\beta \mathrm{AR}$ has been used as a model of the human $\beta$-receptor complex because changes in lymphocyte $\beta A R$ properties have been shown to parallel changes in $\beta A R$ in other less accessible tissues (9-11). We and others have demonstrated that $\beta A R$ responsiveness in lymphocytes from hypertensive subjects, as reflected by $\beta$ AR-mediated adenylate cyclase

Address correspondence to Dr. Feldman, Department of Internal Medicine, University of Iowa, Iowa City, IA 52242.

Received for publication 14 July 1986.

1. Abbreviations used in this paper: $\beta \mathrm{AR}, \beta$-adrenergic receptor; $B_{\max }$, $\beta A R$ density; C.V., coefficient of variation; IPIN, [ ${ }^{125}$ I]iodopindolol.

J. Clin. Invest.

(C) The American Society for Clinical Investigation, Inc.

0021-9738/87/01/0290/05 \$1.00

Volume 79, January 1987, 290-294 activity, is reduced compared with normotensive controls (12, 13). Further, we found that this was not due to a reduction in $\beta A R$ concentration but instead was related to an apparent uncoupling of the receptor from the catalytic component of the adenylate cyclase complex (13). The mechanism underlying this uncoupling process is unknown. However, in several in vitro models of $\beta A R$ regulation, uncoupling of the $\beta$-receptor-adenylate cyclase complex has been associated with a physical sequestration of the receptor from the catalytic component (14). The present studies were designed, in part, to assess the role of $\beta A R$ sequestration in the reduction in $\beta A R$ responsiveness observed in lymphocytes from hypertensive subjects.

The second major goal of the present study was to determine whether lymphocyte $\beta$ AR subsensitivity in human hypertension was reversible. We have previously speculated that this defect might represent the normal regulatory response of the lymphocyte- $\beta$ AR complex to the subtle elevations in plasma catecholamines that may occur in some hypertensive subjects (13). However, Insel and Motulsky recently have suggested an alternate hypothesis linking sodium with the alterations in adrenergic receptors reported in hypertension (15). To test this hypothesis, we have studied the effect of alterations in dietary sodium intake on lymphocyte $\beta A R$ properties from normotensive and hypertensive subjects. We demonstrate here that lymphocyte $\beta \mathrm{AR}$ responsiveness is decreased in hypertensive subjects on a high sodium diet. However, when fed a low sodium diet, lymphocyte $\beta \mathrm{AR}$ responsiveness in hypertensive subjects increases to a level not different from that observed in normotensive subjects.

\section{Methods}

Subject protocol. 16 normotensive and 8 borderline hypertensive subjects between the ages of 20 to $31 \mathrm{yr}$ were studied. The hypertensive subjects had diastolic blood pressure of $>90 \mathrm{mmHg}$ intermittently on three screening outpatient measurements and during the study on at least $20 \%$ of morning blood pressure measurements taken in the sitting position or had diastolic blood pressures $>90 \mathrm{mmHg}$ on at least $20 \%$ of continuously monitored ambulatory blood pressures over a 12 - or 24 -h period. The normotensive subjects had no recorded morning blood pressures of $>90 \mathrm{mmHg}$ (on at least 12 occasions) and $<10 \%$ of continuously monitored diastolic blood pressures of $>90 \mathrm{mmHg}$. Hypertensive subjects were without cardiovascular or renal complications and were otherwise without abnormality on medical history and physical examination. No subject received any drugs within $8 \mathrm{~d}$ of the study, and none had previously received any antihypertensive drugs.

All subjects were studied on two occasions on the sixth day after initiation of a high sodium $(400 \mathrm{meq} / \mathrm{d})$ or low sodium $(10 \mathrm{meq} / \mathrm{d})$ diet. Potassium (100 meq/d) and calcium $(325 \mathrm{mg} / 1,000 \mathrm{kcal})$ intake were constant. The diets were administered in the University of Iowa Clinical Research Center. The order of the diets was randomized. Study periods 
were separated by at least $2 \mathrm{wk}$. A blood sample was drawn on the morning of the sixth day after overnight supine rest in the Clinical Research Center, University of Iowa. Before 7 a.m. and before rising, an indwelling catheter was inserted and $20 \mathrm{~min}$ later a $100-\mathrm{ml}$ blood sample was drawn. Blood samples were analyzed for lymphocyte $\beta A R$ properties and plasma catecholamines as described below.

Lymphocyte isolation and broken cell preparations. Lymphocytes were isolated from EDTA-anticoagulated blood according to the method of Boyum (16) but maintained at $4^{\circ} \mathrm{C}$ to inhibit ex vivo alterations in lymphocyte $\beta$ AR properties (17). Cells were washed and broken cell preparations for assays of adenylate cyclase activity made as previously described (18). Intact cell suspensions for radioligand-binding studies were prepared as previously outlined (19).

Assays of adenylate cyclase activity. Assays of adenylate cyclase activity were performed on broken cell preparations according to our previously published methods (18) modified after Salomon et al. (20). Maximal $\beta$ AR mediated adenylate cyclase activity was expressed as the difference in activity in the presence of isoproterenol $(100 \mu \mathrm{M})$ and GTP $(100 \mu \mathrm{M})$ compared with activity in the presence of GTP alone. Maximal nonreceptor-mediated activity was determined by the addition of $\mathrm{NaF}$ $(10 \mathrm{mM})$ in the absence of GTP. Data are presented as the relative increase in adenylate cyclase activity by isoproterenol or $\mathrm{NaF}$. This method of expressing the data was selected prospectively, consistent with our previous studies (18) on the basis of two major considerations. First, in preliminary studies it was determined that the coefficient of variation (C.V.) was significantly lower when stimulated enzyme activity was expressed relative to basal activity (C.V. $=10 \%)$ rather than absolutely (i.e., as pmol cAMP/min per mg protein) $($ C.V. $=21 \%$ ). Second, although the absolute levels of basal and stimulated adenylate cyclase activity may differ in $\mathrm{T}$ and $\mathrm{B}$ lymphocyte populations, relative stimulation does not $(21,22)$.

Radioligand-binding studies. $\beta$ AR-binding studies were performed in intact lymphocytes according to our previously described methods with the use of [ $\left.{ }^{125} \mathrm{I}\right]$ iodopindolol (IPIN; $2.2 \mathrm{Ci} / \mu \mathrm{mol}$, New England Nuclear, Boston, MA) at $25^{\circ} \mathrm{C}(19)$. For saturation-binding studies, eight concentrations of IPIN (10-100 pM) were used in each assay. Nonspecific binding was defined as that binding not blocked by propranolol $(1 \mu \mathrm{M})$. The proportion of nonsequestered $\beta$ ARs was determined by the proportion of specific IPIN-binding sites blocked by the hydrophilic ligand CGP-12177. In preliminary studies we demonstrated that at a concentration of $30 \mu \mathrm{M}$, CGP-12177 effectively competed for $>90 \%$ of lymphocyte $\beta$ AR-specific binding sites under control conditions (19). However, with agonist exposure resulting in functional desensitization, the same concentration of CGP-12177 was only effective in competing for $\sim 50 \%$ of specific binding sites, consistent with sequestration of a proportion of the total $\beta A R$ population away from the cell surface. In each study, the proportion of CGP-12177 accessible $\beta$ ARs was calculated from the mean of: \% CGP-12177 competable binding/\% propranolol competable binding, at each of eight concentrations of IPIN.

Radioligand-binding data were analyzed using a computerized curvefitting program (SCAFIT) and estimates derived for $\beta$ AR density $\left(B_{\max }\right)$ and affinity for IPIN $\left(K_{\mathrm{D}}\right)(23)$.

In vitro desensitization protocol. To investigate further possible alterations in lymphocyte $\beta$ AR regulation, we also studied $\beta A R$ properties after in vitro exposure of lymphocyte $\beta$ ARs to the $\beta$-agonist isoproterenol. One-half of each blood sample was incubated with isoproterenol $(10 \mu \mathrm{M}$ for $10 \mathrm{~min}$ ) according to the method of Motulsky et al. (24) and radioligand-binding studies and assays of adenylate cyclase activity performed as described above.

Plasma catecholamine assay. Plasma norepinephrine levels were determined for the paired dietary periods by high performance liquid chromatography-electrochemical detection (Smith Kline Bio-Sciences, Van Nuys, CA) in seven hypertensive and nine normotensive subjects.

Statistical analysis. The statistical significance of differences between groups (hypertensive vs. normotensive) or dietary periods (high sodium vs. low sodium) was analyzed as follows: for normally distributed observations (i.e., plasma catecholamines, $B_{\max }$, basal adenylate cyclase activity), a two-tailed $t$ test was used. A paired $t$ test was used for comparisons between high and low sodium diets and an unpaired $t$ test for comparisons between normotensive and hypertensive subjects. However, observations of isoproterenol- and NaF-stimulated adenylate cyclase activity when expressed as the relative increase in activity over basal levels cannot be normally distributed. Therefore, the statistical significance of differences between these parameters was determined by Wilcoxon's signed ranks for paired observations or Wilcoxon's two-group rank sum tests (as appropriate).

Following Bonferroni correction for a two-way comparison, $P<0.025$ in a two-sided test was accepted as the minimum level of significance. All data are expressed as the mean \pm SEM.

\section{Results}

During the high sodium diet lymphocyte $\beta$ AR-mediated adenylate cyclase activity was significantly $(P<0.025)$ decreased in hypertensive $(24 \pm 5 \%)$ compared with normotensive subjects $(41 \pm 4 \%)$ (Fig. 1). The absolute increase in adenylate cyclase activity stimulated by isoproterenol was comparably reduced in lymphocytes from hypertensive subjects-hypertensive: $26 \pm 6$ $\mathrm{pmol} \mathrm{cAMP} / \mathrm{min}$ per $\mathrm{mg}$ protein vs. normotensive: $42 \pm 4 ; P$ $<0.025$. In contrast, $\mathrm{NaF}$ (nonreceptor)-stimulated adenylate cyclase activity was not different between the two groups (hypertensive, $272 \pm 11 \%$; normotensive, $282 \pm 14 \%$ ). The reduction in $\beta \mathrm{AR}$-mediated adenylate cyclase activity in hypertensives was not associated with a decrease in $B_{\max }$ as determined in radioligand-binding studies (Table I). To determine whether this apparent uncoupling of the lymphocyte $\beta A R$ in hypertensive subjects was due to receptor redistribution, we assessed the proportion of $\beta$ AR-specific IPIN binding blocked by CGP-12177, a hydrophilic ligand that can compete effectively only with $\beta$ ARs accessible at the cell surface under the conditions of our experiments. As Table I shows, the proportion of CGP-12177-accessible sites was not different between groups. Therefore, reduced $\beta A R$ responsiveness in lymphocytes from hypertensive subjects could not be explained by either an absolute decrease in $B_{\max }$ or by a functional redistribution of the receptor from the cell surface.

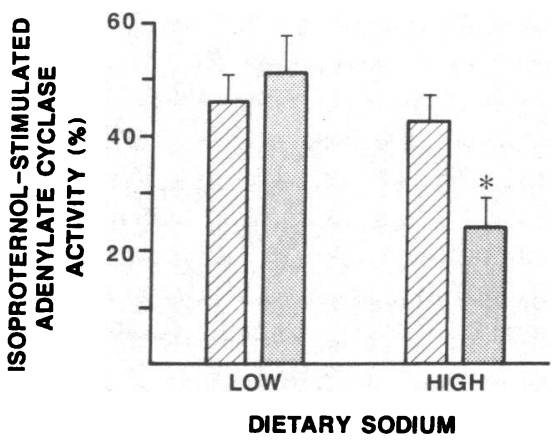

Figure 1. Alterations in lymphocyte $\beta \mathrm{AR}$ responsiveness with dietary sodium intake: normotensive vs. hypertensive subjects. Normotensive $(n=16)$ and hypertensive $(n=8)$ subjects were studied after $5 \mathrm{~d}$ of a high sodium (400 meq/d) and a low sodium (100 meq/d) diet. Data is expressed as the relative increase in adenylate cyclase activity stimulated by isoproterenol $(100 \mu \mathrm{M})$. The data represent the mean \pm SEM. Hatched bars, normotensive; stippled bars, hypertensive. ${ }^{*} P<0.025$ vs. both normotensive subjects fed a high sodium diet and hypertensive subjects when fed a low sodium diet. 
Table I. Alterations in IPIN Binding with Changes in Dietary Sodium

\begin{tabular}{llll}
\hline & Dietary sodium & B $_{\max }$ sites/cell & $\begin{array}{l}\text { \% CGP-12177 } \\
\text { accessible sites }\end{array}$ \\
\hline Normotensive & High & $820 \pm 93$ & $93 \pm 1$ \\
& Low & $771 \pm 80$ & $93 \pm 2$ \\
Hypertensive & High & $952 \pm 210$ & $93 \pm 1$ \\
& Low & $766 \pm 99$ & $93 \pm 1$ \\
\hline
\end{tabular}

These data represent the mean $\pm \mathrm{SEM}$ of $B_{\max }$ and the proportion of nonsequestered receptors (\%CGP-12177 accessible sites) in lymphocytes from normotensive and hypertensive subjects studied while on high sodium and low sodium diets. No significant differences between normotensive and hypertensive subjects nor between high and low sodium dietary periods were apparent for either $B_{\max }$ or \%CGP-12177 accessible sites.

During the low sodium diet, five out of eight hypertensive subjects but only one of 16 normotensive subjects demonstrated a $>5 \mathrm{mmHg}$ decrease in diastolic blood pressure as measured on the final three mornings of the diet. Plasma norepinephrine concentrations increased while on the low sodium diet in both hypertensive subjects (high sodium, $181 \pm 24 \mathrm{pg} / \mathrm{ml}$; low sodium, $384 \pm 67 \mathrm{pg} / \mathrm{ml} ; P<0.025$ ) and normotensive subjects (high sodium, $165 \pm 22 \mathrm{pg} / \mathrm{ml}$; low sodium, $298 \pm 29 \mathrm{pg} / \mathrm{ml} ; P<0.025$ ). However, while on neither diet did plasma catecholamine concentrations differ between normotensive and hypertensive groups.

On the low sodium diet, lymphocyte $\beta A R$ properties in hypertensive but not normotensive subjects were significantly altered. A low sodium diet augmented $\beta$ AR-mediated adenylate cyclase activity in hypertensive subjects (low sodium, $51 \pm 7 \%$, high sodium, 24 $\pm 5 \%, P<0.025$ ) (Fig. 1). The absolute increase in adenylate cyclase activity stimulated by isoproterenol was comparably augmented (low sodium: $45 \pm 7 \mathrm{pmol}$ cAMP/min per $\mathrm{mg}$ protein above basal activity, high sodium: $26 \pm 6, P$ $<0.025)$. However, in normotensive subjects, the low sodium diet did not alter $\beta$ AR-mediated adenylate cyclase activity (low sodium, $46 \pm 5 \%$; high sodium, $42 \pm 4 \%$ ).

In hypertensive subjects, the increase in adenylate cyclase activity was receptor specific. A low sodium diet did not augment NaF-stimulated adenylate cyclase activity (low sodium, $265 \pm 20 \%$; high sodium, $272 \pm 11 \%$ ). Basal activity was also unchanged (low sodium, $102 \pm 7 \mathrm{pmol} \mathrm{cAMP} / \mathrm{min}$ per $\mathrm{mg}$ protein; high sodium, 104 \pm 9 ). Further, changes in $\beta A R-$ mediated adenylate cyclase activity that occurred in hypertensive subjects on a low sodium diet were not associated with any increase in $B_{\max }$, which in fact tended to decrease on the low sodium diet (Table I).

To determine if any alterations in in vitro lymphocyte $\beta A R$ regulation were apparent in either normotensive or hypertensive subjects, lymphocyte $\beta$ AR properties were compared after samples were incubated with isoproterenol. The extent of reduction in CGP-12177-accessible binding (reflecting receptor redistribution) after agonist exposure was not different between hypertensive vs. normotensive subjects under either dietary condition (Table II). Similarly, the extent of reduction in isoproterenolstimulated adenylate activity after agonist exposure (reflecting the extent of functional desensitization) was not significantly
Table II. Agonist-induced Alterations in Adenylate Cyclase Activity and \% CGP-12177-Accessible Binding

\begin{tabular}{llll}
\hline & $\begin{array}{l}\text { Dietary } \\
\text { sodium }\end{array}$ & $\begin{array}{l}\text { Reduction in relative } \\
\text { isoproterenol-stimulated } \\
\text { adenylate cyclase activity }\end{array}$ & $\begin{array}{l}\text { Reduction in percentage } \\
\text { CGP-12177- } \\
\text { accessible sites }\end{array}$ \\
\hline \multirow{2}{*}{ Normotensive } & & $\%$ & $\%$ \\
& High & $27 \pm 5$ & $36 \pm 3$ \\
Hypertensive & Low & $32 \pm 5$ & $41 \pm 2$ \\
& High & $13 \pm 7$ & $37 \pm 1$ \\
& Low & $39 \pm 7$ & $34 \pm 7$
\end{tabular}

The data represent the mean difference between paired samples. Blood samples taken from each subject during each dietary period were split. One sample was exposed to the agonist isoproterenol $(10 \mu \mathrm{M}$ for 10 $\mathrm{min}$ ) then washed. Broken cell preparations (for adenylate cyclase studies) and intact cell preparations (for radioligand-binding studies) were made in parallel. The reduction in isoproterenol-stimulated adenylate cyclase activity and \%CGP-12177 accessible sites was expressed as the difference between samples prepared with and without exposure to agonist. No significant differences between normotensive and hypertensive subjects nor between high and low sodium dietary periods were apparent.

different between groups or dietary periods. However, the extent of reduction in adenylate cyclase activity tended to be less in hypertensive subjects while on the high sodium diet $(P=0.044$ vs. the low sodium diet).

\section{Discussion}

The present studies suggest that dietary sodium is an important regulator of lymphocyte $\beta A R$ responsiveness in hypertension. The findings demonstrate that: $(a) \beta A R$ responsiveness in lymphocytes from hypertensives is significantly decreased on a high sodium diet; (b) after a $10-\mathrm{meq} / \mathrm{d}$ sodium diet, $\beta$ AR responsiveness in hypertensives is increased to a level not different from normotensive subjects; and (c) the decrease in lymphocyte $\beta A R$ responsiveness apparent in hypertensives on a high sodium diet is not due to $\beta A R$ sequestration.

Our data indicate that the alterations in $\beta A R$ responsiveness described in this study are receptor specific. Although alterations in the proportion of $\mathrm{T}$ and $\mathrm{B}$ lymphocytes were not monitored in this study and could account for changes in adenylate cyclase activity, we do not believe this could explain our findings. As previously noted, stimulated adenylate cyclase activity, when expressed relative to basal levels, appears to be independent of the proportion of $\mathrm{T}$ and $\mathrm{B}$ cells $(21,22)$. Furthermore, if the alterations described were nonspecific effects (e.g., changes in T/B cell populations) or due to a nonreceptor specific effect (e.g., on the guanine nucleotide regulatory protein or catalytic component), $\mathrm{NaF}$ and/or basal adenylate cyclase activity would have been expected to change in parallel with isoproterenol-stimulated adenylate cyclase activity. In fact, basal activity and NaF-stimulated activity were not different between normotensive and hypertensive subjects and unchanged by dietary sodium.

Animal studies have consistently demonstrated reduced $\beta \mathrm{AR}$ responsiveness with hypertension (1-8). However, studies in humans, specifically using the human lymphocyte $\beta A R$ as a model system, have demonstrated more variable results $(12,13$, 
25, 26). Our previous studies demonstrated that lymphocyte $\beta A R$ responsiveness was decreased in hypertensive subjects when fed a "normal" (150 meq/d) sodium diet (13). The present studies indicate that this decrease is still apparent in lymphocytes from hypertensive subjects fed a high ( $400 \mathrm{meq} / \mathrm{d})$ sodium diet, but is corrected when hypertensive subjects are fed a low sodium diet. We might, therefore, suggest that heterogeneous sodium intake by hypertensive subjects may in part account for the variability in the results of studies of human $\beta A R$ responsiveness. Other important differences that could account for this variability may relate to heterogeneity of subject populations studied by other investigators in terms of the extent of hypertension, and in age (which is independently associated with a reduction in lymphocyte $\beta$ AR responsiveness) (27). In our studies, the hypertensive populations consisted entirely of younger subjects with borderline hypertension to minimize potential secondary effects of advanced age and sustained hypertension on $\beta A R$ regulation.

How might dietary sodium regulate $\beta$ AR responsiveness? Dietary salt restriction has been shown to reduce intralymphocytic sodium content in borderline hypertensives (28). Further, sodium has been demonstrated to reduce the potency of agonists for several receptors linked to adenylate cyclase; both for those receptors that inhibit adenylate cyclase activity $\left(\alpha_{2}\right.$-adrenergic and muscarinic cholinergic) and for those that stimulate ( $\beta$ AR) adenylate cyclase activity (15). The mechanism of this $\mathrm{Na}$ effect is unclear and could be due to effects either directly on the receptor or indirectly via the guanine nucleotide regulatory proteins of inhibition and stimulation $\left(G_{s}, G_{i}\right)$. However, it should be stressed that the effect could not be due to a simple direct effect of sodium because it was apparent in broken cell preparations assayed in the absence of sodium.

In normotensive subjects, we found that dietary sodium does not conisistently alter lymphocyte $\beta$ AR properties. These findings are in contrast to those of Fraser et al. who noted an increase in lymphocyte $B_{\max }$ in broken cell preparations from normotensive subjects on a high sodium diet (29). However, important differences between studies preclude direct comparison. In their study, lymphocyte $\beta A R$ adenylate cyclase activity was not measured. Further, the diet was administered over a longer period ( 10 vs. $5 \mathrm{~d}$ in our study).

Our present studies demonstrate the effects of severe dietary sodium restriction in $\beta A R$ responsiveness. This level of restriction is rarely possible in clinical practice. Whether a more moderate level of dietary sodium intake is sufficient to correct the defect in $\beta A R$ responsiveness is unknown. Further, the effect of longer term sodium restriction has not been addressed in the present study. However, our study does demonstrate that the reduction in $\beta A R$ responsiveness in lymphocytes from hypertensive subjects is corrected by severe sodium restriction. This suggests an important role for sodium in the impairment of $\beta A R$ responsiveness in the hypertensive state.

\section{Acknowledgments}

We thank Cynthia Lai, Kathy Thede-Reynolds, and Beth Patel for their technical assistance in performing these studies; Chris Sinkey, R.N. for coordinating the subject protocol; and Sam Meyer for her assistance in typing this manuscript. We also thank Allyn Mark, M.D. for his critical review of the manuscript.

This work was supported by Public Health Service grants HL 3250101 and HL 32296-02 and grant RR 059 from the Clinical Research
Center Program. Dr. Feldman is a George Morris Piersol Research and Teaching Scholar of the American College of Physicians.

\section{References}

1. Cohen, M. L., and B. A. Berkowitz. 1976. Decreased vascular relaxation in hypertension. J. Pharmacol. Exp. Ther. 916:396-406.

2. Borkowski, K. R., and M. Porter. 1984. An altered $\beta$-adrenoreceptor-mediated modulation of noradrenaline-induced vasoconstriction in spontaneously hypertensive rat mesenteric arteries. J. Auton. Pharmacol. 4:27-31.

3. Katovich, M. J., E. E. Soltis, E. Iloeje, and F. P. Field. 1984. Time course alterations in vascular adrenergic responsiveness in the DOCA/ NaCl-treated rat. Pharmacology. 29:173-180.

4. Bhalla, R. C., and Sharma, R. V. 1982. Characteristics of hormonestimulated adenylate cyclase activity in vascular smooth muscle: altered activity in spontaneously hypertensive rat. Blood Vessels 19:109-116.

5. Shutz, W., G. Steurer, E. Tuisl, and O. Kraupp. 1984. The cardiac and brain microvessel adenylate cyclase system in deoxycortisone acetatehypertensive rats. J. Cardiovasc. Pharmacol. 6:325-330.

6. Amer, M. S., A. W. Gomoll, J. L. Perhach, Jr., H. C. Ferguson, and G. R. McKinney. 1974. Aberrations of cyclic nucleotide metabolism in the hearts and vessels of hypertensive rats. Proc. Nat. Acad. Sci. (USA) 71:4930-4934.

7. Bhalla, R. C., R. V. Sharma, and S. Ramanathan. 1980. Ontogenetic development of isoproterenol subsensitivity of myocardial adenylate cyclase and $\beta$-adrenergic receptors in spontaneously hypertensive rats. Biochim. Biophys. Acta. 632:497-506.

8. Triner, L., Y. Vulliemoz, M. Verosky, and W. M. Manger. 1975. Cyclic adenosine monophosphate and vascular reactivity in spontaneously hypertensive rats. Biochem. Pharmacol. 24:743-745.

9. Brodde, O. E., R. Kretsch, K. Ikezono, H. R. Zerkowski, and J. C. Reidemeister. 1986. Human $\beta$-adrenoceptors: relation of myocardial and lyphocyte $\beta$-adrenoceptor density. Science (Wash. DC) 231:15841585.

10. Colucci, W. S., R. W. Alexander, G. H. Williams, R. E. Rude, B. L. Holman, M. A. Konstam, J. Wynne, G. H. Mudge, Jr., and E. Braunwald. 1981. Decreased lymphocyte beta-adrenergic-receptor density in patients with heart failure and tolerance to the beta-adrenergic agonist pirbuterol. N. Engl. J. Med. 305:185-190.

11. Aarons, R. D.; A. S. Nies, J. G. Gerber, and P. B. Molinoff. 1983. Decreased beta adrenergic receptor density on human lymphocytes after chronic treatment with agonists. J. Pharmacol. Exp. Ther. 224:1-6.

12. Lima, D. R., and P. Turner. 1982. Beta-blocking drugs increase responsiveness to prostacyclin in hypertensive patients. Lancet. 2:444.

13. Feldman, R. D., L. E. Limbird, J. Nadeau, D. Robertson, and A. J. J. Wood. 1984. Leuckocyte $\beta$-receptor alterations in hypertensive subjects. J. Clin. Invest. 73:648-653.

14. Stiles, G. L., M. G. Caron, and R. J. Lefkowitz. 1984. $\beta$-adrenergic receptors: biochemical mechanisms of physiological regulation. Physiol. Rev. 64:661-743.

15. Insel, P. A., and H. J. Motulsky. 1984. A hypothesis linking intracellular sodium, membrane receptors, and hypertension. Life Sci. 34:1009-1013.

16. Boyum, A. 1968. Isolation of mononuclear cells and granulocytes from human blood. Scand. J. Clin. Lab. Invest. 21(Suppl. 97):77-89.

17. De Blasi, A., S. Cotecchia, M. Fratelli, and M. Lipartiti. 1986. Agonist-induced $\beta$-adrenergic receptor internalization on intact human mononuclear leukocytes: effect of temperature of mononuclear leukocyte separation. J. Lab. Clin. Med. 107:86-94.

18. Feldman, R. D., G. D. Park, and C. Y. C. Lai. 1985. The interaction of verapamil and norverapamil with $\beta$-adrenergic receptors. $C i r$ culation 72:547-554.

19. Thede-Reynolds, K. R., H. J. Motulsky, and R. D. Feldman. 
1986. Temperature dependent binding of hydrophilic $\beta$-adrenergic receptor ligands to intact human lymphocytes. Life Sci. 39:1325-1334.

20. Salomon, Y., C. Londos, and M. Rodbell. 1974. A highly sensitive adenylate cyclase assay. Anal. Biochem. 58:541-548.

21. Carpentieri, U., J. J. Minguell, and F. H. Gardner. 1981. Adenylate cyclase and guanylate cyclase activity in normal and leukemic human lymphocytes. Blood 57:975-978.

22. Mendelsohn, J., and J. Nordberg. 1979. Adenylate cyclase in thymus-derived and bone marrow-derived lymphocytes from normal donors and patients with chronic lymphocytic leukemia. J. Clin. Invest. 63:1124-1132.

23. Feldman, R. D., L. E. Limbird, J. Nadeau, G. A. FitzGerald, D. Robertson, and A. J. J. Wood. 1983. Dynamic regulation of leukocyte beta adrenergic receptor-agonist interactions by physiological changes in circulating catecholamines. J. Clin. Invest. 72:164-170.

24. Motulsky, H. J., E. M. S. Cunningham, A. DeBlasi, and P. Insel. 1986. Desensitization and redistribution of $\beta$-adrenergic receptors on human mononuclear leukocytes. Am. J. Physiol. 250:E583-D590.
25. Brodde, O. E., A. E. Daul, N. O'Hara, and A. M. Khalifa. 1985. Properties of $\alpha$-and $\beta$-adrenoceptors in circulating blood cells of patients with essential hypertension. J. Cardiovasc. Pharmacol. 7(Suppl. 6):S162S167.

26. Lima, D. R. A., S. Kilfeather, and P. Turner. 1981. Lymphocyte cyclic AMP in hypertensive patients treated with $\beta$-adrenoceptor blocking drugs. Br. J. Clin. Pharmacol. 11:120P.

27. Feldman, R. 1986. Physiological and molecular correlates of agerelated changes in the human $\beta$-adrenergic receptor system. Fed. Proc. 45:48-50.

28. Ambrosioni, E., F. V. Costa, C. Borghi, L. Montebugnoli, M. F. Giordani, and B. Magnani. 1982. Effects of moderate salt restriction on intralymphocytic sodium and pressor response to stress in borderline hypertension. Hypertension 4:789-794.

29. Fraser, J., J. Nadeau, D. Robertson, and A. J. J. Wood. 1981. Regulation of human leukocyte beta receptors by endogenous catecholamines. Relationship of leukocyte beta receptor density to the cardiac sensitivity to isoproterenol. J. Clin. Invest. 67:1777-1784. 